\title{
Aerials and their influence on World Surfing League surfer performance (WSL flights)
}

\section{Os aéreos e sua influência no desempenho dos surfistas da Liga Mundial de Surf (Aéreos WSL)}

\author{
Luis Eduardo Tietzmann 1 \\ (iD) https://orcid.org/0000-0003-2449-2396 \\ Emanoel Adão Pacheco ${ }^{1}$ \\ (D) https://orcid.org/0000-0002-9859-7620 \\ Hélio Roesler \\ (D) https://orcid.org/0000-0002-1631-6961 \\ Suzana Matheus Pereira ${ }^{1}$ \\ (D) https://orcid.org/0000-0003-4413-5583
}

Abstract - This research aimed to verify whether the number of airplanes run by surfers in the 2016 Word Surf League (WSL) men's season and their grades were related to their final classification in the events and season. Were viewed 3475 waves from 49 surfers and selected for analysis 275 waves. Spearman's correlation test, one-way ANOVA, and t-test, with $\mathrm{p} \leq 0.05$, were used for statistical analysis. The air proved to be an effective maneuver in isolated clashes, helped to reach the finals and decide events, but did not prove to be the main determinant of the season's final standings. The average of the marks attributed to the reverse 360 aerial was significantly higher than the notes attributed to the reverse aerial, however, the variables the position of the surfer in front or back to wave and whether or not to grab the board edge did not present significant differences.

Key words: Athletic performance; Sport; Surf.

Resumo - Esta pesquisa teve como objetivo verificar se a quantidade de aéreos executados pelos surfistas na temporada masculina da Word Surf League (WSL) de 2016 e suas respectivas notas tiveram relação com a classificação final deles nos eventos e na temporada. Foram visualizadas 3475 ondas de 49 surfistas e selecionadas para analise 275 ondas. Utilizou-se o teste de correlação de Spearman, ANOVA um fator e o teste $t$, com $p \leq 0.05$, para análise estatística. $O$ aéreo se mostrou uma manobra eficaz em confrontos isolados, ajudou a chegar às finais e a decidir eventos, mas não se mostrou ser o principal determinante para a classificação final da temporada. A média das notas atribuidas ao aéreo reverse 360 foi significativamente maior que as notas atribuídas ao aéreo reverse, no entanto, as variáveis posiçôes do surfista de frente ou de costas para onda e agarrar ou não borda da prancha, não apresentaram diferenças significativas.

Palavras-chave: Desempenho atlético; Esporte; Surf.
1 Universidade do Estado de Santa Catarina. Laboratório de Biomecânica Aquática. Florianopolis, SC. Brasil.

Received: 09 September 2019 Accepted: 08 January 2020

How to cite this article Tietzmann LE, Pacheco EA, Roesler H, Pereira SM. Aerials and Their Influence on World Surfing League Surfer Performance (WSL flights). Rev Bras Cineantropom Desempenho Hum 2020, 22:e67473. DOl: http://dx.doi.org/10.1590/19800037.2020v22e67473

Copyright: This work is licensed under a Creative Commons Attribution 4.0 International License. 


\section{INTRODUCTION}

The World Surfing League (WSL) is the body that coordinates professional surfing competitions on the world stage. All year long, the best surfers compete against each other in the Championship Tour to determine who will be the champion of the season. Surfers accumulate points and are ranked according to their position during the ten or eleven events of the year, many held on beaches that have the best waves on the planet. The surfer who gets the most points at the end of the season is world champion of that year. To decide the champion of each event, 36 surfers compete against each other in two or three surfers' heats up to the grand final. Each event is made up of seven rounds, with the quarterfinals, semifinals and finals covering rounds five, six and seven respectively, with heats composed of two surfers. The surfer with the highest sum of his two best waves wins the heat. Judgment is based on five criteria: commitment to degree of difficulty; innovative and progressive maneuvers; combination of great maneuvers; variety of maneuvers; speed, power and fluidity. The emphasis on certain elements varies with site characteristics and day conditions ${ }^{1}$.

The surfer's ability to use the wave as a ramp, take off in air course and return to the wave again is called $\mathrm{air}^{2}$. The air is a maneuver considered as a powerful tool to achieve better results and lead to victory in the clashes of the world's surfing elite ${ }^{3}$. In addition to meeting WSL judgment criteria, air-containing waves score significantly higher than non-airborne waves ${ }^{3-5}$. A wave that performs only one aerial maneuver may receive the highest score $^{3}$. However, due to the high level of knee and ankle injury ${ }^{6}$ and the completion rate being only around $50 \%{ }^{4,5,7}$, air is a high-risk maneuver and it is not always, and not all surfers, that perform efficiently.

Previous studies analyzing WSL competitions have correlated the surfer's bottom-turn curve with the judges' scores ${ }^{8}$, showing that larger curves tend to receive higher grades. They found that waves with air score higher than waves without $\operatorname{air}^{3-5}$, that the criteria used by the referees correlate significantly with the grades ${ }^{9}$, that the best in the ranking receive higher grades and have smaller oscillations in performance ${ }^{10}$, and that variability in The performance of competitive surfers is higher than that of sports athletes such as running, swimming and weightlifting ${ }^{11}$. Good performance in competitive surfing is subject to factors such as: physical capabilities $^{12,13}$, mastery of technique, wave and board type $\mathrm{e}^{2,12,14}$, cognitive $^{10}$ and tactical aspects such as choice of wave and right maneuver ${ }^{3,5}$, aspects psychological and motivational ${ }^{15}$. In addition, competitors must meet the judgment criteria ${ }^{1,9}$ and may be influenced by the interpretation of the arbitration board ${ }^{10}$. Despite the multiplicity of factors, many studies encourage coaches and surfers to increase the frequency of execution and complexity of air in order to improve the grade and competitive performance ${ }^{3-5,10}$.

From the foregoing, this research aimed to verify whether the frequency of executions and air marks given to each surfer in the 2016 WSL men's season were related to the final classification in both the events and the 
final result of the season. It was also verified, if there was influence on the notes received by the airmen as to: the type of air, the execution of front or the back and not to grab the board. The results may help surfers and coaches decide on the importance of running air in training and competitions, based on the influence of this maneuver on the final ranking of the best surfers in the world.

\section{METHOD}

\section{Participants}

The study included 49 surfers $(29.2 \pm 5.5$ years, $177 \pm 6 \mathrm{~cm}, 74.8 \pm 5.8 \mathrm{~kg})$ who took part in at least one event in the main division of the 2016 WSL men's season. To verify if there was a relationship between the frequency of air and its grades with the final classification of surfers in the events and the season, only 30 subjects were included, using as an inclusion criterion to have participated in at least nine events of the season.

\section{Procedures}

The data were collected from videos made available on the WSL official website, using the heat analyzer feature, which allows the visualization of each wave surfed and the identification of the received note. We analyzed all the events of the 2016 WSL men's main season Championship Tour division. We observed the best two waves of each surfer per round, from round one, to the final, and all the waves from the quarter to the final, totaling 3475 waves. Only the airborne waves were selected (the surfer and the board should lose contact with the wave).

From the first round to the final, for each selected air, the following performance variables were verified: score received, air type, surfer's position in front or back to wave and whether or not to hold the board. With the waves from the quarterfinals until the final, the frequency of hits and attempts, and the relationship of air with the classification in the final phase of the event was verified.

The airs were classified into six types: (1) "air" type, the surfer should take off in an air trajectory and return to a non-rotating wave; (2) In "inverted air," the surfer should rotate the air $180^{\circ}$ in the longitudinal axis in the direction of his trajectory, land with the nozzle facing the wave, and not complete $360^{\circ}$ rotation after landing (interrupting the rotation in the wave base); (3) In reverse air, the surfer should rotate $180^{\circ}$ in the longitudinal axis in the air in the direction of his trajectory, land with the surfboard tip and complete $360^{\circ}$ rotation after landing (not interrupting the rotation in the wave base); (4) In the "reverse $360^{\circ}$ aerial", the surfer should perform the $360^{\circ}$ full air rotation on the longitudinal axis, landing with the board's nozzle facing the beach; (5) in the alley-oop, the surfer should rotate in the air $180^{\circ}$ in the longitudinal axis in the opposite direction of his trajectory; (6) In the backflip, the surfer should perform a $360^{\circ}$ air rotation on the back transverse axis, combined with a $90^{\circ}$ rotation on the longitudinal axis. 


\section{Statistical analysis}

The software Excel 2010, IBM SPSS Statistic, version 20.0 and Past 318 were used. Initially measurements of central tendency (average) and dispersion (standard deviation) were made. To verify the normality of the data, depending on the sample size, the Kolmogorov-Smirnov and Shapiro-Wilk tests were used. The Levene test was used to verify the homogeneity of the variances. As the classification of surfers in events and season is an ordinal variable and air frequency data did not show normality, to verify the relationship between these two variables, the Spearman correlation test (rs) was chosen. For the comparison of the grades between the air types, we used the one-way analysis of variance, with Tukey post-hoc. In this analysis the type of backflip air was not inserted, since it occurred only once. Comparisons of the scores of the variables air, position (front or back) and grip (no grip or grip) were performed using Student's t-test for independent samples. For all tests performed, a significance level of $p \leq 0.05$ was used.

\section{RESULTS}

The average grade of round 1 to finals was $7.2( \pm 1.3)$. The hit percentage in air performance in the $2016 \mathrm{WSL}$ season was $52.5 \%$. A correlation of $0.69(\mathrm{p}<0.001)$ was found between the frequency of attempts of each surfer and the frequency of successfully executed air. The vast majority of aerials (92\%) were performed by surfers in the wavefront position (Table 1). Of the airs executed when surfers had their backs to the wave, the "reverse air" was performed 8 times and the "reverse air 360" 6 times. The "reverse air" stood out as the most executed type (78.4\%). There was a significant difference in the comparison between "reverse air" and "reverse air 360" scores $(\mathrm{F}=3.08, \mathrm{p}=0.017)$.

Table 1. Comparison between means of air types.

\begin{tabular}{lccc}
\hline Type & Note (SD) & fr $(\%)$ & p-value \\
\hline 1 - Air & $7.6(1.1)^{\mathrm{ab}}$ & $13(7.4)$ & 0.017 \\
2 - Inverted Air & $6.7(1.8)^{\mathrm{ab}}$ & $5(2.8)$ & \\
3 - Reverse Air & $7.1(1.3)^{\mathrm{a}}$ & $138(78.4)$ & \\
4 - Reverse 360 Air & $8.3(1.2)^{\mathrm{b}}$ & $10(5.7)$ & \\
5 - Alley 0op & $7.5(1.8)^{\mathrm{ab}}$ & $9(5.1)$ & \\
6 - Backflip & 10.0 & $1(0.6)$ & \\
Total & & $176(100 \%)$ & \\
\hline
\end{tabular}

Note. The letters $(a, b)$ indicate the comparison of groups; Equal letters indicate no significant difference; Different letters indicate presence of significant difference for $p \leq 0.05$. ( $\left.{ }^{*} p \leq 0.05\right) ;\left({ }^{* *} p<0.001\right)$

No differences were found between the marks given to the airmen regarding the position of the surfers on the wave (front or back) and on the surfers' grip on the board (hand grip or not), Table 2.

Analyzing the relationship between the frequency of air performance and the surfers classification in the events (Table 3), the Jeffres Bay event 
(RSA) was the event that showed the highest significant correlation $(\mathrm{r} s=-0.62, \mathrm{p}<0.001, \mathrm{n}=36)$. When related In the air scores with the surfers' ratings at the events, the Snapper Rocks (AUS) event stood out with the highest significant correlation ( $r s=-0.51, \mathrm{p}<001, \mathrm{n}=24)$. Considering only the finals of the events (from Wednesdays to the finals), the event at Postinho beach in Rio de Janeiro showed a strong correlation with rs $=-0.75$ $(p=0.047)$, between the frequency of airs successfully performed by each surfer on the drums and their final classification in the event $(f r=12, n=8)$.

Table 2. Comparison of grade averages between the two positions of surfers on the wave and between the two types of grip on the board $(n=176)$.

\begin{tabular}{lccc}
\hline Variables & Note (SD) & fr (\%) & $\mathrm{p}$-value \\
\hline Air Position & & & \\
Front & $7.2(1.3)$ & $162(92)$ & $\mathrm{p}=0.447$ \\
Back & $7.6(1.9)$ & $14(8)$ & \\
Grab & & & \\
No hold & $7.2(1.4)$ & $117(66.5)$ & $\mathrm{p}=0.410$ \\
With grab & $7.3(1.2)$ & $59(33.5)$ & \\
\hline
\end{tabular}

Note. The letters $(a, b)$ indicate the comparison of groups; Equal letters indicate no significant difference; Different letters indicate presence of significant difference for $p \leq 0.05$. ( $\left.{ }^{*} p \leq 0.05\right)$; $\left({ }^{* *}\right.$ $p<0.001)$.

Table 3. The correlations of air frequency and its scores with the classification of surfers in each event of the season $(n=36, n=176)$.

\begin{tabular}{lcccccc}
\hline & & \multicolumn{3}{c}{ Frequency x Ranking } & \multicolumn{2}{c}{ Notes x Ranking } \\
\hline Event & $\mathrm{Fr}$ & $(\%)$ & rs & $\mathrm{p}$-value & rs & p-value \\
Snapper Rocks (AUS) & 24 & $(14)$ & -0.30 & 0.076 & -0.51 & $0.001^{* *}$ \\
Bells Beach (AUS) & 2 & $(1)$ & 0.14 & 0.396 & & \\
Margaret River (AUS) & 15 & $(9)$ & -0.37 & $0.027^{\star}$ & -0.38 & 0.165 \\
Rio de Janeiro (BRA) & 33 & $(19)$ & -0.41 & $0.012^{*}$ & -0.45 & $0.008^{*}$ \\
Namotu (FIJI) & 4 & $(2)$ & -0.07 & 0.656 & 0.54 & 0.455 \\
\hline Jeffres Bay (RSA) & 21 & $(12)$ & -0.62 & $0.001^{* *}$ & -0.13 & 0.566 \\
Thehupoo (PYF) & 1 & $(1)$ & -0.13 & 0.430 & & \\
Trestles (USA) & 32 & $(18)$ & -0.35 & $0.033^{*}$ & -0.15 & 0.410 \\
Landes (FRA) & 17 & $(10)$ & -0.42 & $0.009^{*}$ & -0.41 & 0.095 \\
Peniche (POR) & 24 & $(14)$ & -0.22 & 0.196 & 0.00 & 0.984 \\
Pipeline (HAW) & 3 & $(2)$ & 0.09 & 0.599 & 0.86 & 0.666 \\
Total & 176 & $(100)$ & & & & \\
\hline
\end{tabular}

Note. $\left.{ }^{*} p \leq 0,05\right) ;{ }^{* *} p<0,001$

By smoothing the correlation of air frequency with the classification of surfers in the season (Figure 1), it was possible to observe a significant relationship between the two variables ( $r s=-0.39, p=0.030, n=30)$. Likewise, Figure 2 shows a significant correlation between grades and classification in the season ( $\mathrm{rs}=-0.34, \mathrm{p}<0.001, \mathrm{n}=156)$.

\section{DISCUSSION}

In the present study, the percentage of air hits was $52.5 \%$, higher than 


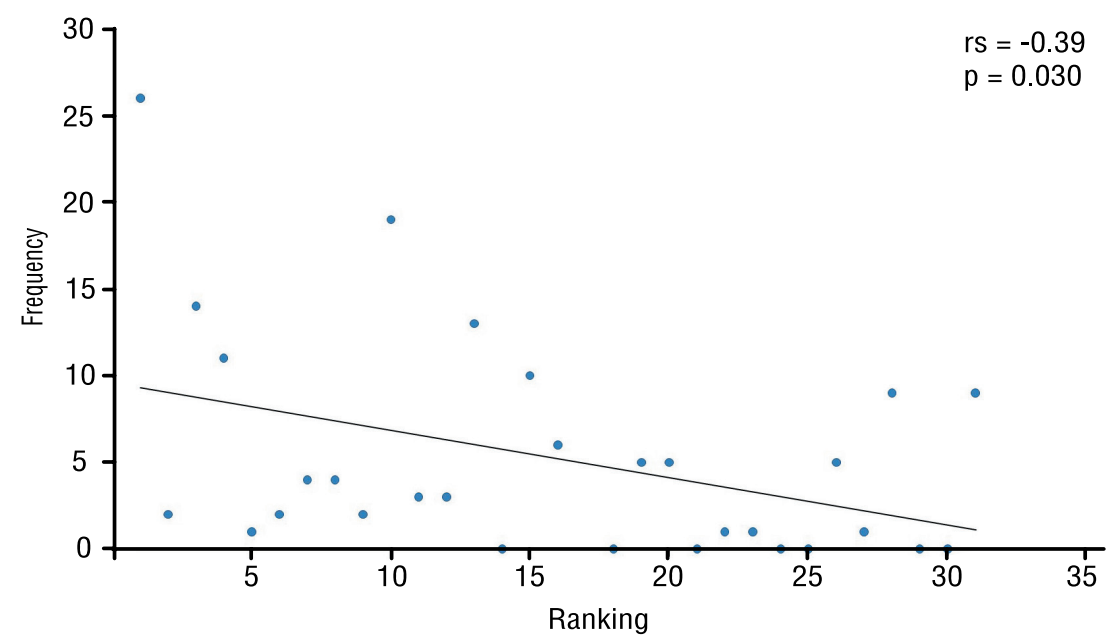

Figure 1. Correlation between air frequency and season rating of surfers ( $f r=156, n=30$ ).

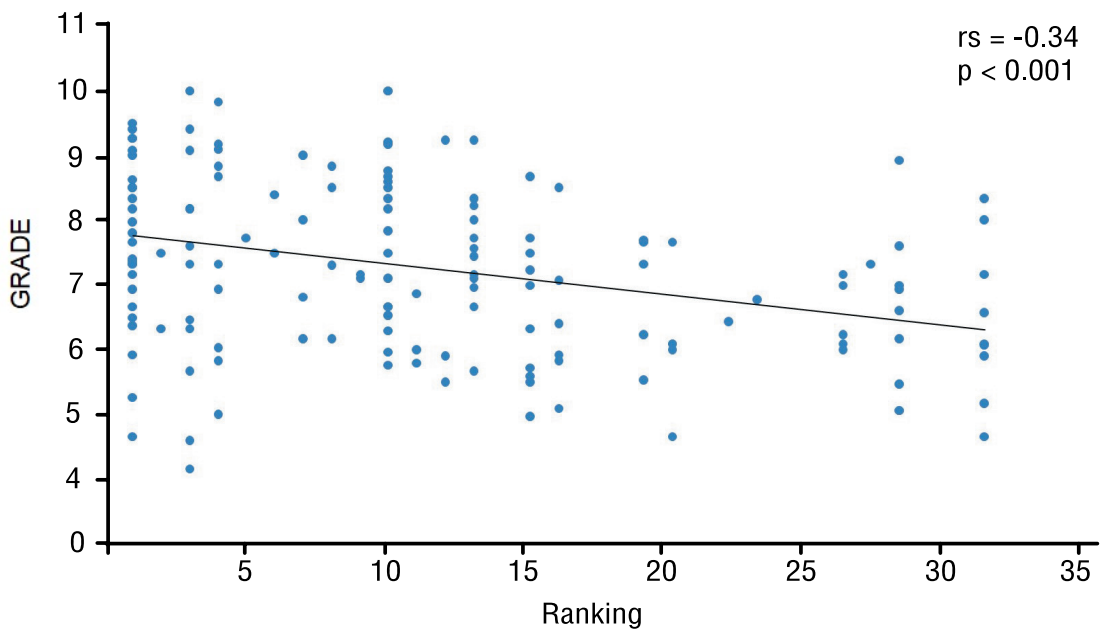

Figure 2. Correlation between air scores and surfer ratings for the season $(n=156)$.

the $48.5 \%$ reported in the study by Lundgren et al. ${ }^{5}$ which analyzed the 2012 season, but below the 55\% found by Forsyth et al. ${ }^{7}$ in 2015. It was noticed, however, that some surfers are working at rates well above average. The third in the rankings in the 2016 season hit eight aerials out of ten attempts. This surfer, according to Garcia and Romero ${ }^{15}$, seems to have high motivation for success, which makes him more confident in performing his air. The correlation between the frequency of attempts and the frequency of air hits ( $r s=0.69$ ) shows that the frequency of hits is linked to the frequency of attempts and that those surfers who hit more also tried harder, suggesting that for surfers to benefit from the possible points resulting from this maneuver should, in addition to increasing the percentage of hits, increase the frequency of attempts.

In the midst of competitive surfing it is believed that air where surfers do not grab the board by hand score higher than those they do. However, it seems that this difference is not being valued by the judges. The lack of significant difference in the mean of the grades between grabbing and not 
grabbing the board can be explained, in part, by the fact that airplanes performed in both ways receive both low and high grades. Other variables may be interfering with this analysis, since the score is the result of a subjective analysis made by the judges. Among the many possible variables, we can cite the "combination of great maneuvers" described as a judgment criterion in Article 165 of the $\mathrm{WSL}^{1}$ rulebook, and also the influence of the wave itself being surfed, as cited by Lundgren et al. ${ }^{3,5}$ there are waves with higher scoring potential than others.

The top scorers were the "backflip air", which received a score of 10 , but could not enter the group comparison analysis because it had no statistical representation, and the "reverse 360 air", which proved to be the largest maneuver complexity. Ferrier et $\mathrm{al}^{4}$, with a smaller sample size $(\mathrm{n}=121)$, separated into groups the ones in which the surfer held his hand on the board, from those in which he did not, finding no significant difference between the average grades of the different types. by air. Ferrier et al. ${ }^{4}$ described two attempts of the backflip air type in 2014, and Lundgren et al. ${ }^{3}$ mentioned that a wave with the reverse 360 air maneuver received the grade 10 in 2012. In the present study, four airwaves were rated 10 in the season, of which three were waves where the surfer performed only one maneuver, two "reverse 360 airs" and one "backfip". The fourth wave in question featured a "reverse air" performed alongside other powerful turning maneuvers.

In events where many air runs were performed and correlations with the ranking were weak or not significant, most air flights were performed by surfers who did not reach the quarterfinals and finals. Jeffres Bay (RSA) was the event that presented the strongest correlation of air frequency with the ranking $(\mathrm{rs}=-0.62)$. In this place the waves are traditionally big and hollow, but in this competition they were smaller. This may have favored air rides and these somehow seem to have contributed to the surfers' classification for the final stages of the competition. However, the winner of the event did not fly any aircraft, it is clear that he used other elements available in the competition to win.

The strong correlation between the number of air hits on the drums and the ranking found in the Rio de Janeiro (BRA) event finals suggests that air use can be decisive in finals and can help win events. Some airs didn't make it into the sum of the surfers, but notably put them in an advantage position on the drums. In the first semifinal of the aforementioned event, the champion of the season and event, after hitting a 7.17 air in his first wave, could wait more calmly for bigger waves due to the air's advantage. At the end of the battery ended up taking two tubes with notes 9.80 and 8.93, and winning the confrontation.

Studies by Lundgren et al. ${ }^{3}$ and Ferrier et al. ${ }^{4}$ have shown that airwaves score higher than those that do not contain this maneuver. It can be said that the air increases the chances, but does not guarantee the victory in the battery, because in $47.2 \%$ of the air surfers did not beat their batteries. Likewise, it seems that this competition format where the ranking is 
given by the sum of the two best waves, did not benefit those surfers who performed the most air, nor those who got the highest marks for their air.

The number of airplanes for each surfer and his grades had weak correlations with their classification in the season, $\mathrm{rs}=-0.39$ and $\mathrm{rs}=-0.34$, respectively. The second highest-performing air surfer of the season (19th) ranked tenth in the ranking, and the second surfer performed only two airs in the season, which helps to explain the poor correlation of air frequency with the season rating. The two surfers who received the top ten for their air in the circuit did not win the events in which they did the air. The third in the ranking, during the event of Rio de Janeiro (BRA), was the surfer who performed the most air and received the highest marks, including the only backflip of the entire circuit, and even then came in third place. Likewise, the first placed in the circuit did not perform aerials grade ten and despite having performed many aerials in the season, in 15 of them (42\%) did not win the batteries, nor won in the three events where he performed more aerials (6.5.5). In addition, the winners of such events did not submit any air tickets.

Waves do not always offer the ideal conditions to successfully fly. They must be dug like a ramp and at the same time provide situations for the surfer to perfectly perform the takeoff, air and landing phases. Lundgren et al..$^{5}$ observed that aerials were performed on $6 \%$ of the total waves surfed in the 2012 season, and the tubes and turn maneuvers were performed on 16 and $78 \%$ of the waves, respectively. In the stages of Thehupoo, Fiji, Pipeline, where the surfer's ability to ride inside the tubes prevails, almost no aerials were performed in the 2016 season, as found by Lundgren et al. ${ }^{5}$.

The study by Peirão and Santos ${ }^{9}$ found differences in the amount of air in relation to the wave size. In the present study, in Margaret River (AUS) when the waves were bigger and in Bells Beach (AUS) when they were fuller, less aerials were performed. As the waves grew, the airs lost space for the turning maneuvers and the tubes. The air was very effective in small to medium waves that allowed one to two maneuvers.

The poor correlations of the air with the classification of surfers in the 2016 season indicate that there are other factors that interfere with the result. For Villanueva and Bishop ${ }^{12}$, there are two types of factors that can influence performance: those that are within reach and depend directly on surfers, such as physical, psychological, technical and tactical skills; and external factors, which may benefit or hinder surfers' scores such as equipment, wave condition, arbitration and opponents.

\section{CONCLUSION}

Analyzing the airs of the 2016 Word Surf League (WSL) Men's Championship Tour season, it was concluded that what the difference in scoring was influenced by the type of air performed, with the "reverse 360 air" being the highest scoring air. It was not relevant for scoring, whether dur- 
ing the air the surfer grabbed the board or not or if the wave was surfed from the front or the back.

It can be said that air is not the main determining maneuver in the ranking of the surfing elite. There are other factors that deserve attention from coaches and surfers, which are suggested to be analyzed by further studies. Nonetheless, the air proved effective in isolated clashes, helped surfers reach the event finals and decide events.

\section{COMPLIANCE WITH ETHICAL STANDARDS}

\section{Funding}

This research did not receive any specific grant from funding agencies in the public, commercial, or not-for-profit sectors. This study was funded by the authors.

\section{Ethical approval}

This research is in accordance with the standards set by the Declaration of Helsinki

\section{Conflict of interest statement}

The authors have no conflict of interests to declare.

\section{Author Contributions}

Conceived and designed the experiments: L.E.T; S.M.P Analyzed the data: L.E.T; S.M.P. Contributed reagents/materials/analysis tools: E.A.P; H.R. Wrote the paper: L.E.T; S.M.P.

\section{REFERENCES}

1. WSL (Word Surf League). WSL Rule Book 2017: Santa Mônica. 2017; Available from:<http://www.wordsurfleague.com/pages/rules-and-regulations $>[2017$ Nov 22].

2. Moreira MAAG. Matriz de análise das tarefas desportivas: sistema de classificação estrutural- modelo taxinômico do surf. [Tese de Doutorado - Faculdade de Motricidade Humana]. Lisboa (Portugal); Universidade Técnica de Lisboa; 2007.

3. Lundgren L, Dunn M, Nimphius S, Sheppard J. The importance of aerial manouvers in elite competitive surfing performance. J Aust Strength Cond 2013; 21(1):70-72

4. Ferrier B, Sheppard J, Newton RU, Nimphius S. The importance of aerial manouvre variations on competitive surfing performance. J Aust Strength Cond 2014;.22(5):135-138.

5. Lundgren L, Newton RU, Tran TT, Dunn M, Nimphius S, Sheppard J. Anylisis of manouvres and scoring in competitive surfing. International J Sports Sci Coach 2014; 9(4):663-669.

6. Lundgren L, Butel M, Brown T, Nimphius S, Sheppard J. High ankle sprain: The new elite surfing injury? Int Sport Med J 2014; 4(2): 321-327.

7. Forsyth J, Riddioford HDL, Steele JR. Characterising successful aerial manouvres in professional surfing competitions. XXXIV International Conference on Biomecanichs in Sports. Tsukuba (Japan): 2016, p.601-604.

8. Souza PC, Rocha MA, Nascimento JV. Correlação da técnica bottom turn com as notas atribuídas no surf de alto rendimento. Rev Bras Cineantropom Desempenho Hum 2012; 14(5): 554-560. 
9. Peirão R, Santos SG. Critérios de julgamento em campeonatos internacionais de surfe profissional. Rev Bras Cineantropom Desempenho Hum 2012; 14(4): 439-449.

10. Farley ORL, Raymond E, Secomb JL, Ferrier B, Lundgren L, Tran TT, et al. Scoring analysis of the men, s 2013 world championship tour of surfing. Int J Aquatic Res Education 2015; 9(1): 38-48.

11. Villanueva MA, Mujica I, Bishop D. Variability of competitive performance assessment of elite surfboard riders. J Strength Cond Res 2010; 24(1): 135-139.

12. Villanueva MA, Bishop D. Physiological aspects of surfboards riding performance. Austrália. Sports Med 2005; 35 (1): 55-70.

13. Tran TT, Lundgren L, Secomb J, Farley ORL, HaffGG, Seitz LB, et al. Comparison of physical capacities between nonselected and selected elite male competitive surfers for the national junior team. Int J Sports Physiol Perform 2015; 10:178-182.

14. Scarfe BE, Elwany MHS, Mead ST, Black KP. The Science of surfing waves and surfing breaks. Proceedings of the 3rd International Surfing Reef Symposium. Ralan (New Zealand): 2003, p.37-59.

15. Garcia FG, Romero DN. Autoestima y competitividade em uma selección juvenil peruana de surf. Rev Ibero Psico Ejerc Desp 2009; 4(2): 253-269.

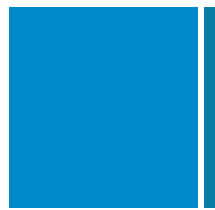

Corresponding author

Luis Eduardo Tietzmann

Francisco Thomaz dos Santos Highway, South Swamp Frame,

Florianópolis, Brazil, No. 5076.

Zip code: 88066000

Email: projetosurftag@hotmail.com 